\title{
Editorial: El Niño-Southern Oscillation - observations and modeling
}

\author{
Pascale Braconnot ${ }^{1}$, C. Brierley ${ }^{2}$ and S.P. Harrison 3,4 \\ 'Laboratoire des Sciences du Climat et de I'Environnement, unité mixte CEA-CNRS-UVSQ, Saclay, France; pascale.braconnot@lsce.ipsl.fr \\ 2Department of Geography, University College London, UK; ${ }^{3}$ Department of Biological Sciences, Macquarie University, North Ryde, Australia; \\ ${ }^{4}$ Centre for Past Climate Change and School of Archaeology, Geography and Environmental Sciences, University of Reading, UK
}

$T^{\mathrm{n}}$ he El Niño-Southern Oscillation (ENSO) is one of the major climate phenomena affecting our global environment (Figs. 1 and 2), but current understanding of ENSO is limited. Instrumental records are too short to allow us to document its spectrum of variability and there is little knowledge of how variability alters with changes in the climate mean state, for example with anticipated global warming.

In the PAGES news issue "Paired perspectives on global climate change" (2012), Amy Clement highlighted some important issues about the decadal variability, predictability and modeling of ENSO with global warming. As pointed out by Julien Emile-Geay in the same issue, paleoclimate data are a valuable resource to improve our understanding of these issues, even though the past does not provide direct analogs for the future. Analyses of high-resolution paleoclimate indicators and the possibility of long simulations with the same climate models used for future climate projections offer new opportunities for improving our understanding of ENSO. One of the foci of the working group on climate variability in the $3^{\text {rd }}$ phase of the Paleoclimate Modeling Intercomparison Project (PMIP3; Braconnot et al. 2012a) is to foster the synthesis of high-resolution data and the development of new data-model comparison methodologies to examine changes in ENSO.

\section{The future of ENSO research}

The suite of papers presented in this newsletter is one outcome of the PMIP workshop on "Tropical climate variability with a focus on last millennium, mid-Holocene and Last Glacial Maximum" which took place in the south of France in September 2011 and was co-sponsored by PAGES (Braconnot et al. 2012b). The articles provide an overview of high-resolution records and modeling studies that can be regarded as a basis for future ENSO research. Individual contributions address how one can extract ENSOrelevant climate information from tree rings, corals, giant bivalves, or shells, and how modeling can be used to test explicit hypotheses to improve the interpretation of paleoclimate records as well as to infer the mechanisms of climate change. The articles also illustrate some fundamental questions that need to be addressed in preparing multi-proxy reconstructions of past ENSO behavior and in analyzing paleoclimate modeling results. We consider these studies to be the first step towards a comprehensive evaluation of whether climate models incorporate the right physics and feedbacks to reproduce the diversity of ENSO events.

\section{Pulling the pieces together}

An exciting development, showcased in this special issue, is that many different types of records exist that

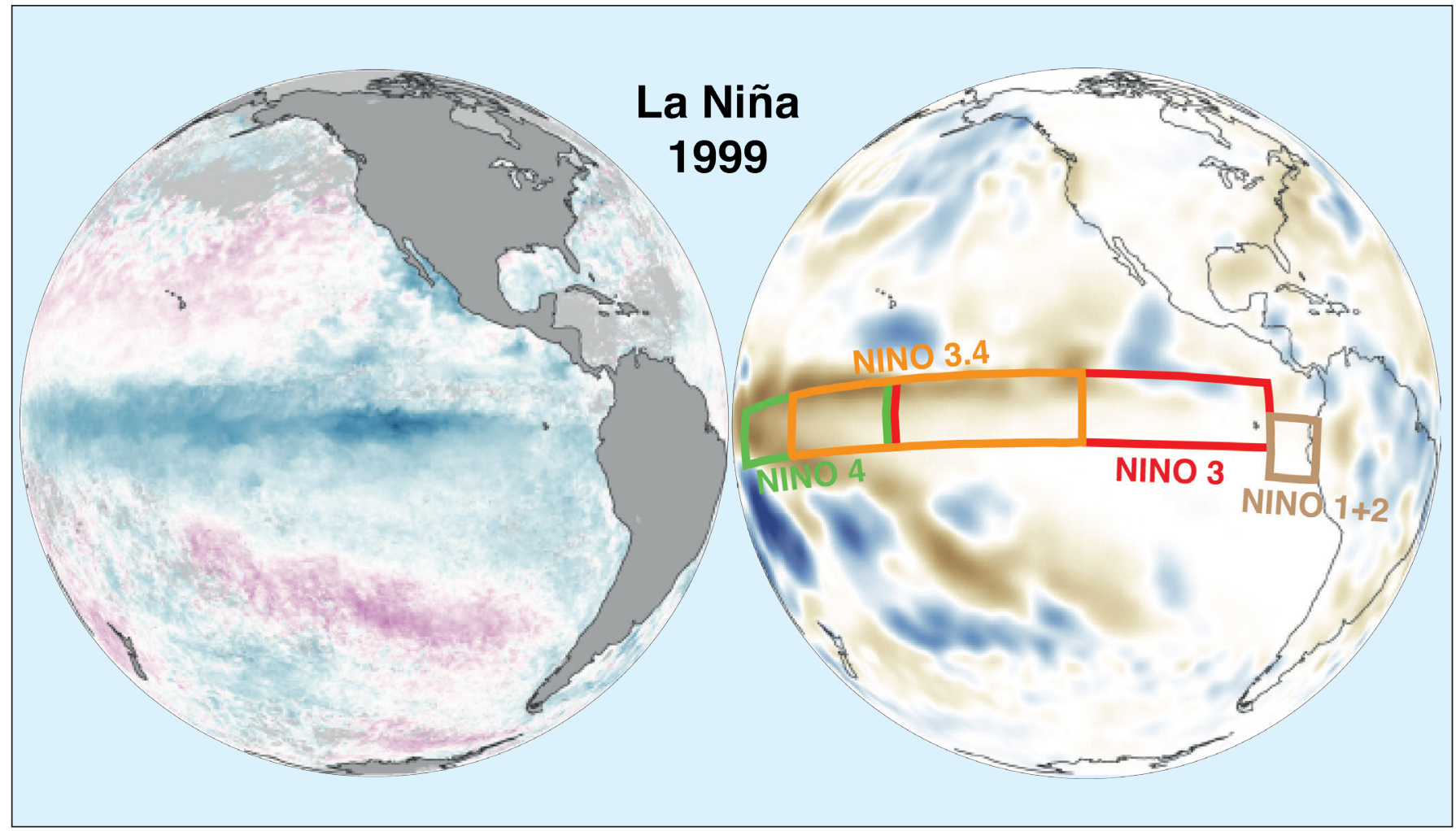

Figure 1: La Niña event of 1999. Left: Positive (purple) and negative (blue) sea surface temperature anomalies. Right: Positive (blue) and negative (brown) rainfall anomalies $(\mathrm{mm})$. The four El Niño regions referred to in the following articles are depicted in the right panel. Images from NASA. 


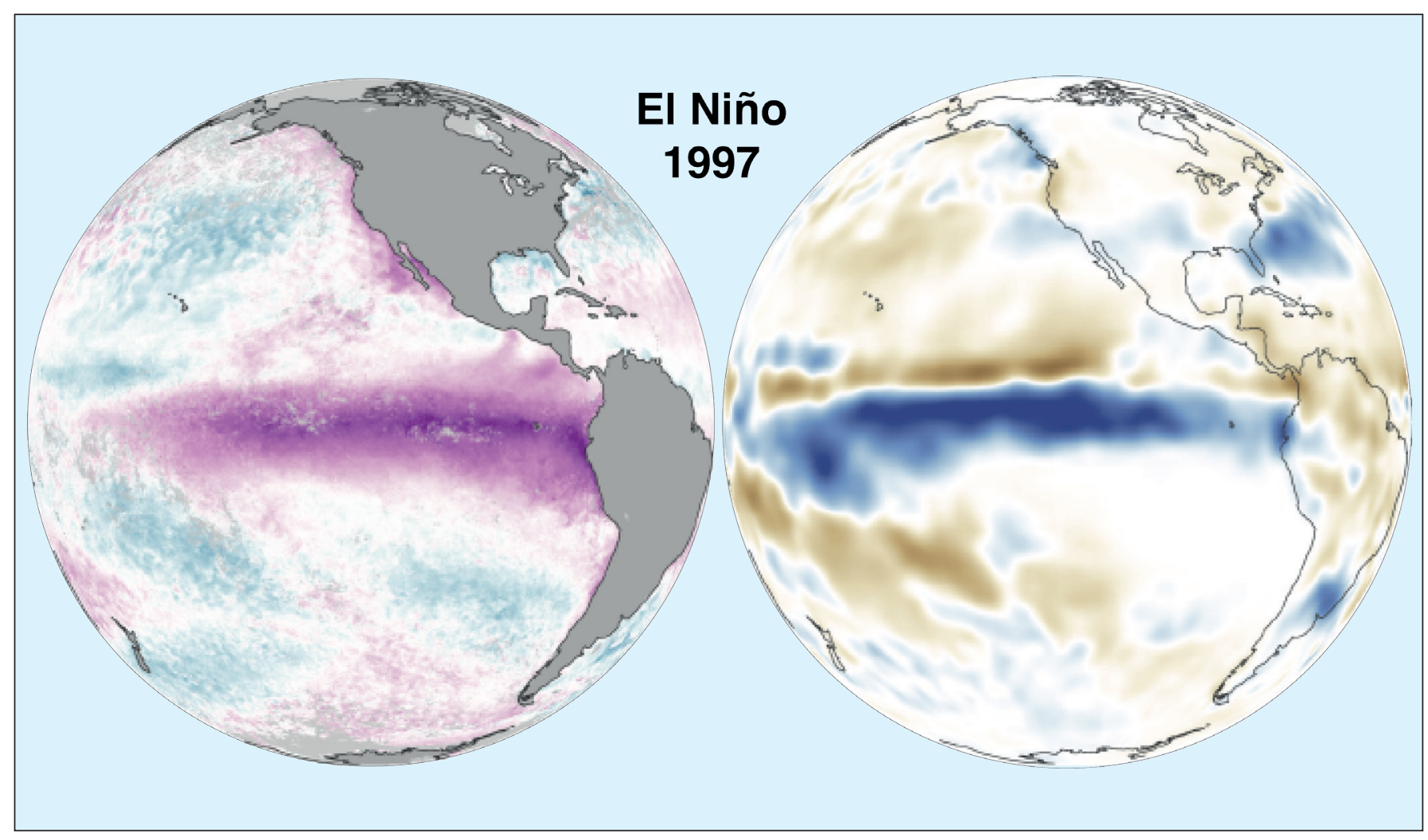

Figure 2: El Niño event of 1997. Left: sea surface temperature anomalies. Blue: negative, purple: positive. Right: Rainfall anomalies (mm). Brown: negative, blue: positive. Images from NASA.

document short term climate variability (see Elliot et al. p. 54 and Carré et al. p. 56) and that pooling information from multiple types of records provides a pan-tropical picture of ENSO. The contributions here and in other recent papers (e.g. Cobb et al. 2013), demonstrate that the process-level understanding of individual records has improved over recent years (see Elliot et al. p. 54 or McGregor et al. p. 52). This includes the recognition that it is rare for paleoclimate records to reflect a single climate variable (e.g. temperature or salinity) or aspect of climate variability (e.g. seasonal phasing or magnitude changes in mean frequency or in extremes). The challenge now is to find ways to synthesize the disparate aspects of the records and to take advantage of the wider range of information available to provide an overview of ENSO variability (see Russon et al. p. 62 or Thompson et al. p. 60).

\section{Modeling improvements}

A second important development is the improvement in modeling capacity and analytical approaches. Coupling between different components of the climate system is notoriously difficult and this poses problems for simulating aspects of the climate system, such as ENSO, that are primarily driven by the coupling between the ocean and atmosphere (see Capotondi et al. p. 58 or Lazareth et al. p. 66). Nevertheless, with improved model physics, increased spatial resolution, more routine incorporation of tracers (e.g. isotopes) and biogeochemistry, and the ability to run much longer simulations, state-of-the-art models are increasingly yielding important insights into ENSO. Model simulations show that ENSO displays non-stationary behavior in space and time, including the strength of ENSO teleconnections (Capotondi et al. p. 58, Merkel et al. p. 68). The simulations imply that the ENSO phenomenon has to be decoupled into different components, such as mean state, hydrology and teleconnections that change independently depending on the forcing (see Braconnot et al. p. 64). The lessons learned from models and their integration with observations pose ambitious challenges to the interpretation of the ENSO-relevant signal in paleoclimate records (Russon et al p. 62, Brierley p. 70, Lazareth et al. p. 66).

\section{Towards data and model integration}

It is a pivotal time for the ENSO community. We see a real need for new activities. First and foremost, there needs to be a more integrated approach to combining data and modeling for hypothesis testing. To facilitate this, the community needs to synthesize more primary data across regions and realms. This will allow us to capitalize on the improvements in process understanding that are emerging from both data analyses and modeling experiments. The other requirement is developing statistical and analytical tools that combine the two sources of information (data and model outputs) to disentangle the evolution of mean state, seasonality, and interannual to decadal variability. To develop these approaches and tools, we see a need for a dedicated activity within the PAGES and PMIP communities that brings together the full range of expertise. This is the only way to answer the fundamental questions about the relationships between the background climate state, the seasonal cycle and ENSO variability.

\section{Selected references}

Full reference list online under:

http://www.pages-igbp.org/products/newsletters/ref2013_2.pdf

Braconnot P et al. (2012a) Nature Climate Change 2: 417-424 Braconnot P, Harrison SP, Tudhope S, Michaut C (2012b) PAGES news 20(1):51-52

Cobb KM et al. (2013) Science 339: 67-70 